\title{
TENSILE PROPERTIES AND FRACTURE MECHANISM OF IN-100 SUPERALLOY IN HIGH TEMPERATURE RANGE
}

\author{
Milan T. Jovanović ${ }^{1}$, Đorđe Drobnjak ${ }^{2}$, Ivana Cvijović-Alagićl ${ }^{*}$, \\ Vesna Maksimović ${ }^{l}$ \\ ${ }^{I}$ Department of Materials Science, Institute of Nuclear Sciences "Vinča", \\ University of Belgrade, Serbia \\ ${ }^{2}$ Faculty of Technology and Metallurgy, University of Belgrade, Serbia
}

Received 03.11.2016

Accepted 11.04.2017

\begin{abstract}
Tensile properties and fracture mechanism of a polycrystalline IN-100 superalloy have been investigated in the range from room temperature to $900{ }^{\circ} \mathrm{C}$. Optical microscopy (OM) and transmission electron microscopy (TEM) applying replica technique were used for microstructural investigation, whereas scanning electron microscopy (SEM) was utilized for fracture study. High temperature tensile tests were carried out in vacuumed chamber. Results show that strength increases up to $700{ }^{\circ} \mathrm{C}$, and then sharply decreases with further increase in temperature. Elongation increases very slowly $(6-7.5 \%)$ till $500{ }^{\circ} \mathrm{C}$, then decreases to $4.5 \%$ at $900{ }^{\circ} \mathrm{C}$. Change in elongation may be ascribed to a change of fracture mechanism. Appearance of a great number of microvoids prevails up to $500^{\circ} \mathrm{C}$ resulting in a slow increase of elongation, whereas above this temperature elongation decrease is correlated with intergranular crystallographic fracture and fracture of carbides.
\end{abstract}

Key words: Tensile strength, elongation, microstructure, microvoids, intergranular crystallographic fracture

\section{Introduction}

Nickel-base superalloys, cast and wrought, derive their strength from the mechanism of solid-solution hardening and precipitation hardening, singly or in combination. Most of superalloys contain 6 to 23 wt. $\%$ Cr, primarily for oxidation resistance at elevated temperature, but also for solid-solution hardening [1-3].

The matrix of the nickel-rich solid solution is designated as $\gamma$. The predominantly solid-solution alloys, such as IN-100, contain significant amount of $\mathrm{Al}$, Ti or Nb, added to promote formation of the dispersed second phase - notably $\gamma^{\prime}$. This phase designated

* Corresponding author: Ivana Cvijović-Alagić, ivanac@vin.bg.ac.rs 
as $\mathrm{Ni}_{3}(\mathrm{Al}, \mathrm{Ti})$, and $\eta\left(\mathrm{Ni}_{3} \mathrm{Ti}\right)$ is formed during solidification of alloy. IN-100 is also strengthened by dispersion of non-coherent carbides $\left(\mathrm{MC}, \mathrm{M}_{6} \mathrm{C}, \mathrm{M}_{23} \mathrm{C}_{6}\right)$ and the addition of refractory metal elements, such as Mo and $\mathrm{W}$, as well as interstitials, such as $\mathrm{C}$ and B [4-6]. Generally speaking, IN-100 belongs to a group of cast non-heat treatable superalloys. The amount of the strengthening phase $\gamma$ ' formed after cooling may be $60 \%$ at the maximum and cannot be increased by the following heat treatment. That is why the amount of Ti and $\mathrm{Al}$ in IN-100 is twice higher than in other cast, but heat treatable superalloys (see Table 2 in [7]). It should be noted that the turbine blades fabricated from IN-100 by investment casting were installed in combustion chamber of Rolls Royce jet engines "RR Viper 11“(,G-4 Galeb-4“) and „RR Viper 632“(,G-4 Super Galeb") in as cast condition, i.e. without any previous heat treatment.

To be true, some kind of heat treatment, called high temperature annealing, is performed in the process of coating of IN-100 turbine blades. Coating is performed to protect turbine blades against oxidation and corrosion. A two-step coating process is performed: slurry spraying of nickel-aluminide and iron-aluminide plus iron-chromiumaluminum is followed by pack aluminizing. The coated blades were cyclically furnace tested in air at $1093{ }^{\circ} \mathrm{C}$ for $300 \mathrm{~h}$ [8].

Formation of the second phase in many of the cast alloys begins in the liquid state. Casting conditions (degree of superheating, pouring time, cooling rate and mold temperature) largely control microstructure and subsequent properties. In many of the casting alloys precipitation of the second phase is practically complete when the casting is removed from its mold, and further heat-treatment is often ineffective. Because complete re-solution does not occur in cast alloys, the dispersed second phase and its strengthening effect are retained in these alloys at high service temperatures $[2,6]$.

Modern gas turbine engines for aviation applications are generally considered to exhibit a high level of reliability, and failure rates are considered low. In reality, failures, unfortunately, occur. However, the situation is controlled by the rigid inspection of engines are exposed, and undergoes very strictly inspection. This is also to ensure that almost all failures are detected in the early stage of exploitation. This also ensures that almost all malfunctions are detected in the early stage, and suspected parts are removed from service for replacement or refurbishment before failure.

Turbine blades of jet aircraft engines are working in extremely difficult conditions, i.e. they were subjected to the effects of static and dynamic loads, high temperatures and corrosive atmospheres. Blade failures can be caused by a number of mechanisms under the turbine operating conditions of high rotational speed at elevated temperature. In general, blade failures can be grouped into two categories that are fatigue; including both high (HCF) and low cycle fatigue (LCF) [9] and the second is creep rupture [10].

Therefore, the aim of this paper was to investigate the mechanical properties of IN-100 superalloy at elevated temperatures and to find out the correlation between these characteristics and mechanism of fracture.

The object of this paper is a polycrystalline nickel based superalloy IN-100, which is still used for manufacturing of turbine blades of jet aircraft engines by vacuum melting and investment casting into ceramic shell molds. Although this alloy is somehow obsolete and new and more advanced alloys are used, it is still applied and is not abandoned due to its outstanding high temperature properties. 


\section{Experimental}

According to the manufacturer (Ross and Catherall, England), the nominal composition (wt.\%) of IN-100 superalloy was: $5.5 \mathrm{Al}, 4.5 \mathrm{Ti}, 10 \mathrm{Cr}, 15 \mathrm{Co}$, Mo 3, $1 \mathrm{~V}$, $0.1 \mathrm{~W}, 0.05 \mathrm{Zr}, 0.015 \mathrm{~B}$, while the rest was nickel.

A single-chamber "Leybold-Heraeus" vacuum-induction furnace (Fig. 1a) was used for melting and casting of screw-type samples for tensile tests. Vacuum during melting and pouring was maintained at a level of $2 \times 10^{-2}$ mbar. Pouring temperature was $1480{ }^{\circ} \mathrm{C}$. Samples were investment (precision) cast into ceramic shell molds (Fig. 1b) previously prepared with the special procedure applying several layers of different grain fractions of zircon-silicate powder. To obtain the best quality of castings surface the inner wall of the mold was prepared with the finest powder fraction. The molds were preheated at $800{ }^{\circ} \mathrm{C}$ before casting. The arrangement of cylindrical samples for tensile tests around the central sprue is shown in Fig. 1c. The dimensions of these samples were as follows: $25 \mathrm{~mm}$ gauge length and $3 \mathrm{~mm}$ diameter.
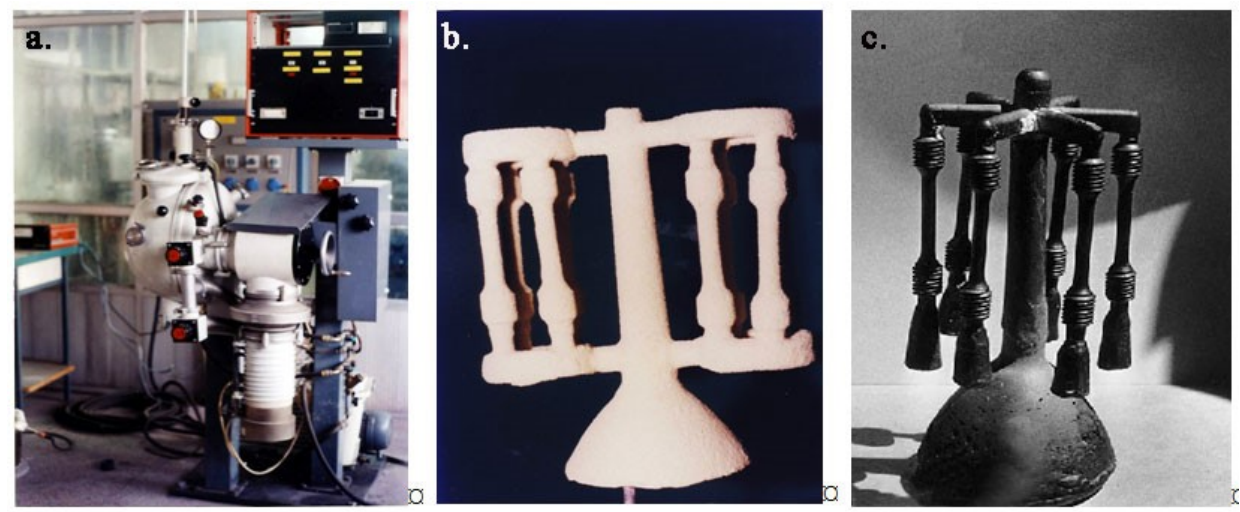

Fig. 1. a) "Leybold-Heraeus" single chamber vacuum-induction furnace;

b) ceramic shell mold for investment casting; $c$. arrangement of investment cast samples for tensile tests.

Microstructural investigations were carried out by optical (OM) and transmission electron microscope (TEM) applying replica technique, whereas for investigation of fracture mechanism scanning electron microscope (SEM) was used. Polished samples for $\mathrm{OM}$ were etched using Marble's reagent, i.e. a mixture of $10 \mathrm{~g} \mathrm{CuSO}_{4}, 50 \mathrm{~mL} \mathrm{HCl}$ and $50 \mathrm{~mL}$ distilled $\mathrm{H}_{2} \mathrm{O}$. The standard replication technique utilizing the vacuum evaporation of carbon followed by gold shadowing, was applied to obtain replicas for TEM. Tensile tests were carried out in a vacuumed chamber (at $1.33 \mathrm{~Pa}$ ) in the temperature range between room temperature and $900{ }^{\circ} \mathrm{C}$. The total time for each test (including heating, dwelling time at corresponding temperature and tensile test) was approximately $40 \mathrm{~min}$. Concerning that elongation to failure varied with temperature and taking into account the strain rate, time to failure at $900{ }^{\circ} \mathrm{C}$ was approximately $40 \mathrm{~min}$, whereas at $500{ }^{\circ} \mathrm{C}$ (the highest elongation) was approximately $45 \mathrm{~min}$. Considering that the microstructure of $\mathrm{IN}-100$ is stable even at $900{ }^{\circ} \mathrm{C}$ (for shorter period of time), this difference has no effect on microstructure. Temperature was controlled by the 
thermocouple Pt-Pt13\%Rh placed just above the sample. Uniaxial tensile tests were performed at a strain rate $\dot{\mathrm{e}}=1.3 \times 10^{-3} \mathrm{~s}^{-1}$.

\section{Results and discussion}

Microstructure of IN-100 superalloy before tensile tests (OM and SEM) is shown in Figs. $2 \mathrm{a}$ and $\mathrm{b}$, respectively. Microstructure consists of the matrix, which is the $\gamma$ phase, small cuboidal intermetallic particles of the $\gamma^{\prime}$ phase and blocky MC carbides. The kidney-like $\gamma-\gamma^{\prime}$ eutectic (E in Fig. 2) appears as a mixture of the lamellar $\gamma^{\prime}$ phase (F in Fig. 2) formed inside the $\gamma$ phase. Black dot (T) formed on the surface of MC carbide (G) may be seen in Fig. 2a. Huang et al. showed by SEM and electron probe microanalysis that black dots, characteristic centers on the surface of some blocky carbides, are of TiN origin. TiN serves as nuclei for formation of $\mathrm{MC}$ or $\mathrm{M}(\mathrm{C}, \mathrm{N})$ carbides in the melt [11].
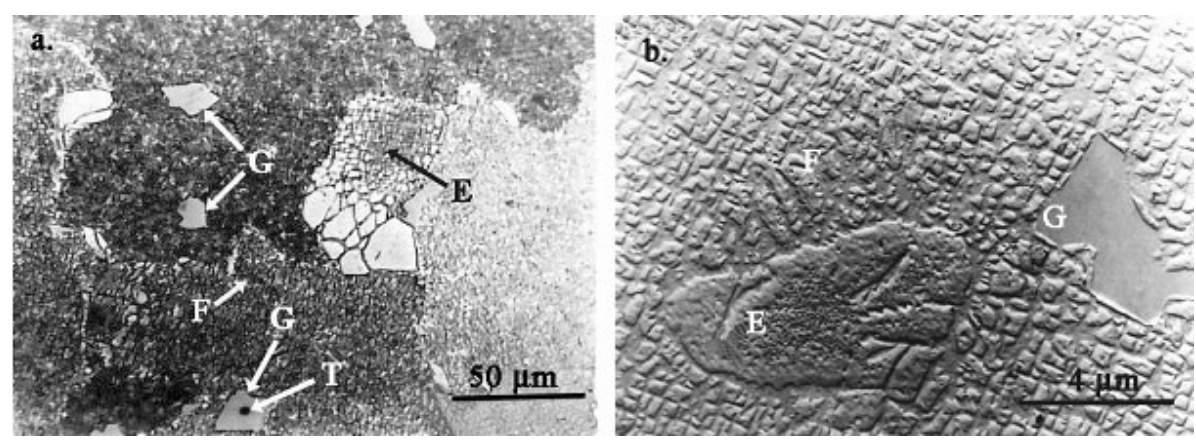

Fig. 2. Microstructure of IN-100 superalloy before tensile tests $a$. OM and

b. TEM replica. $E-\gamma-\gamma^{\prime}$ eutectic, $F-\gamma^{\prime}$ particles, $G$ - blocky MC carbides, T - TiN.

Fig. 3 illustrates change in microstructure due to the effect of high temperature exposure during tensile tests. Compared to microstructure before tests, the most significant changes are visible in eutectics, where lamellae of the $\gamma^{\prime}$ phase become coarser (at $700{ }^{\circ} \mathrm{C}$, Fig. 3a), or they are nearly completely disintegrated (at $900{ }^{\circ} \mathrm{C}$, Fig. $3 b)$.

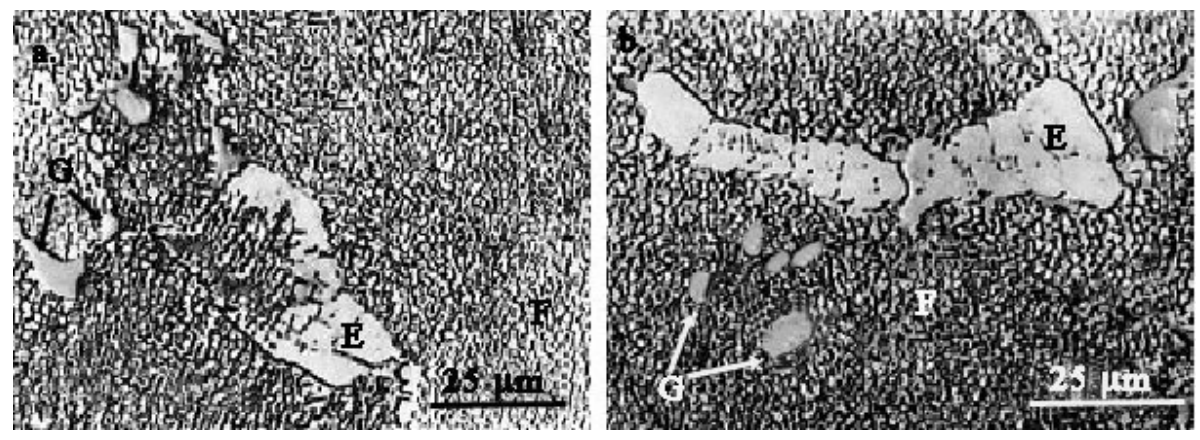

Fig. 3. OM microstructure of IN-100 samples exposed to high temperatures during tensile tests: a. at $700{ }^{\circ} \mathrm{C}$; b. at $900{ }^{\circ} \mathrm{C}$. $E-\gamma$ - $\gamma^{\prime}$ eutectic, $F-\gamma$ ' particles, $G$ - blocky $M C$ carbides. 
The effect of temperature on ultimate tensile strength and elongation to failure is shown in Fig. 4. Strength increases with temperature up to $700{ }^{\circ} \mathrm{C}$ and then suddenly decreases. This increase in strength with temperature is somewhat higher than it was reported in the literature [12] and there is no adequate explanation for such phenomenon. It is possible that dynamic strain aging (DSA), through the interaction of mobile dislocations with $\gamma^{\prime}$ particles, plays a role in increasing strength up to $700{ }^{\circ} \mathrm{C}$. However, for such an explanation there is no direct evidence since the stress-curves were smooth, i.e. no serrations were observed. Serrated yielding, or discontinuous yielding, is regarded as a clear indication for occurrence of DSA. Elongation increases very slowly (from 6 to $7.5 \%$ ) up to $500{ }^{\circ} \mathrm{C}$, but at higher temperatures elongation drops to $4.5 \%$ at $900{ }^{\circ} \mathrm{C}$.

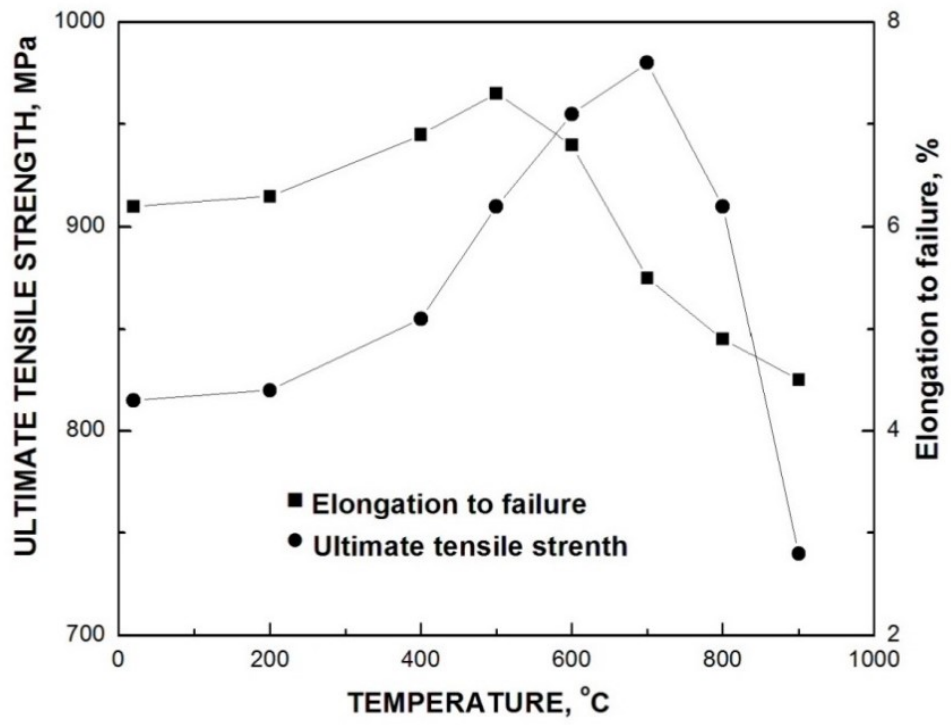

Fig. 4. Change of ultimate tensile strength and elongation to failure of IN-100 superalloy with temperature.

SEM microfractographs of IN-100 superalloy at $500{ }^{\circ} \mathrm{C}$, which correspond to maximal elongation, are shown in Fig. 5. The mixed fracture mode is operating at this temperature, although microvoids prevail on the fracture surfaces. Microvoids (A) appear either on the grain boundaries (Fig. 5a) or occupy rather wide area inside the grain (Fig. 5b). The $\gamma^{\prime}$ phase particles may be seen inside some microvoids (B in Fig. 5c). Sporadic appearance of blocky carbides fracture occurs by delamination of particles (C in Figs. 5a and d). In some rare cases intergranular fracture may be seen (D in Fig. 5a). 

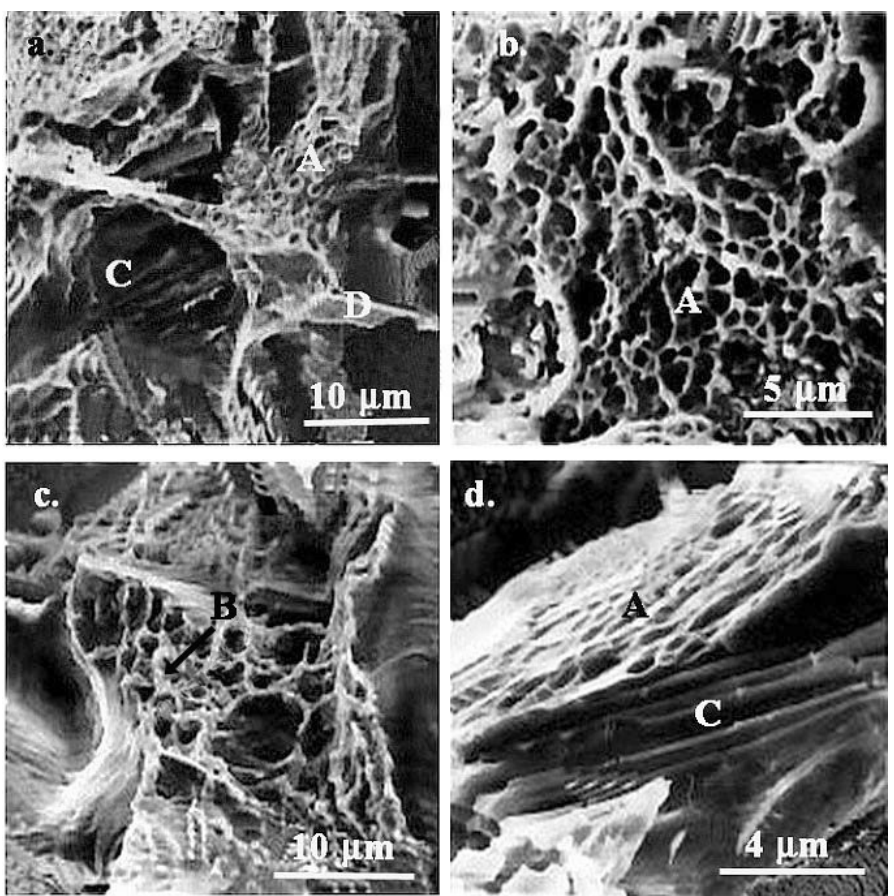

Fig. 5. SEM microfractographs of IN-100 superalloy at $500{ }^{\circ} \mathrm{C}$. A - microvoids, $B$ - the $\gamma$ ' phase particles inside microvoids, $C$-fracture of carbides by delamination, $D$ - intergranular fracture.

SEM microfractographs of IN-100 superalloy at 700 and $900{ }^{\circ} \mathrm{C}$ corresponding to decrease and minimal elongation are shown in Figs. 6 and 7, respectively. Intergranular crystallographic fracture together with carbide fracture prevails at both temperatures. Intergranular fracture occurs along $\{111\}$ sliding planes (D in Figs. 6 bd), similar to results of high temperature fatigue and tensile tests of some nickel base superalloys $[13,14]$ and high temperature test in the hydrogen atmosphere [15].

Thus, from room temperature to $500{ }^{\circ} \mathrm{C}$ the operating fracture mechanism is ductile fracture when microvoids prevail on the fracture surface, whereas in the temperature region from 600 to $900{ }^{\circ} \mathrm{C}$ brittle fracture is predominant fracture mechanism distinguished by a mixture of intergranular crystallographic fracture and carbide fracture. Carbide fracture is very distinct at $900{ }^{\circ} \mathrm{C}$. 

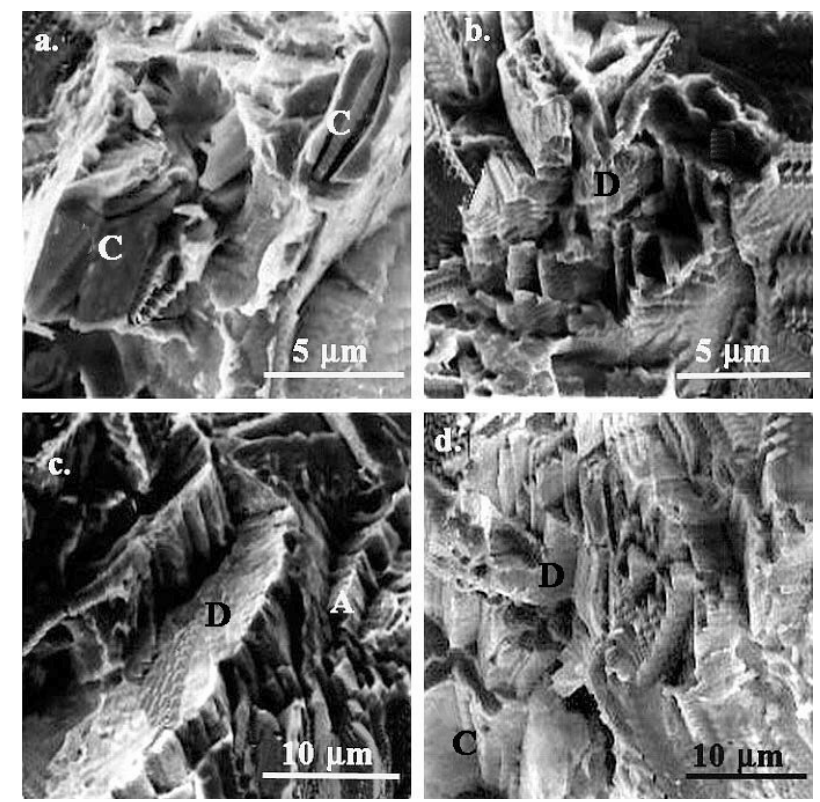

Fig. 6. SEM microfractographs of IN-100 superalloy at $700{ }^{\circ} \mathrm{C} . \mathrm{C}$ - carbide fracture, $D$ - intergranular crystallographic fracture.
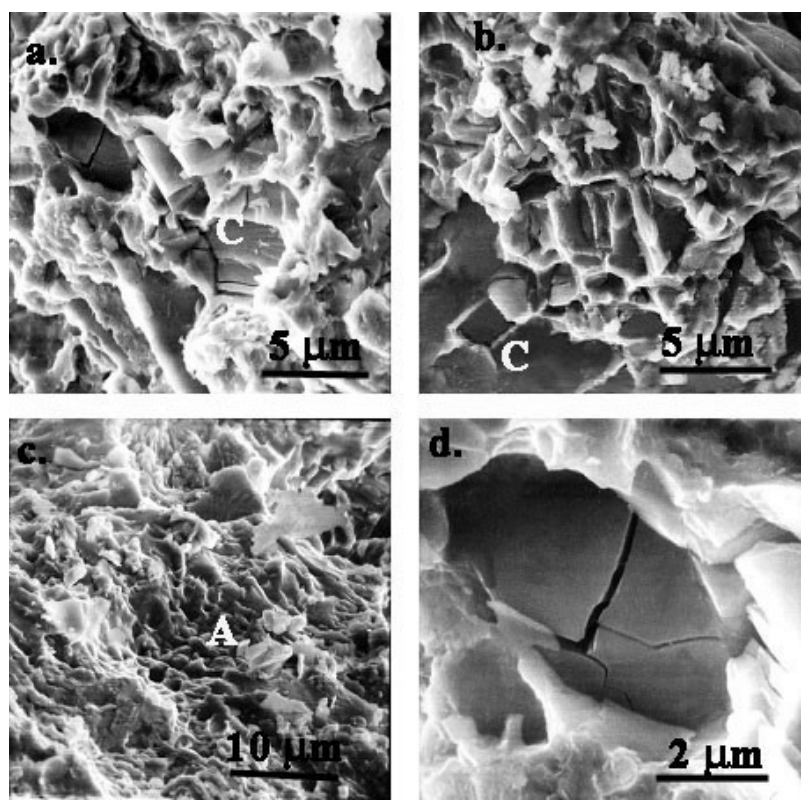

Fig. 7. SEM microfractographs of IN-100 superalloy at $900{ }^{\circ} \mathrm{C}$. A - area with microvoids, Fig. $7 d$ represents higher magnification of fractured carbide in Fig. $7 a$. 
The increase of ultimate tensile strength is a consequence of lower mobility of dislocations which are blocked by the $\gamma$ ' particles. The strength decreases beyond about $700{ }^{\circ} \mathrm{C}$ when the thermal activation is sufficiently violent to allow the dislocations to overcome the obstacles [16].

Taking into account fracture results, decrease of elongation at temperatures above $500{ }^{\circ} \mathrm{C}$ is a consequence of changed mechanism of fracture. Actually, in the lower temperature interval, i.e. from room temperature to $500{ }^{\circ} \mathrm{C}$, the operating fracture mechanism is ductile fracture, whereas for the abrupt decrease of elongation above $500{ }^{\circ} \mathrm{C}$ intergranular crystallographic fracture is responsible.

\section{Conclusion}

The effect of high temperature during tensile tests on fracture mechanism of a polycrystalline IN-100 superalloy was investigated.

Strength increases with temperature up to $700{ }^{\circ} \mathrm{C}$ and then suddenly decreases. Values of elongation increase very slowly (6-7.5\%) up to $500{ }^{\circ} \mathrm{C}$, when the decrease occurs to $4.5 \%$ at $900{ }^{\circ} \mathrm{C}$.

Change in elongation may be ascribed to a change of fracture mechanism. Microvoids prevails in the low temperature range up to $500^{\circ} \mathrm{C}$, resulting in a somewhat higher elongation, whereas the elongation decrease is correlated with intergranular crystallographic fracture and fracture of carbides at temperatures above $500{ }^{\circ} \mathrm{C}$.

\section{Acknowledgement}

This work was financially supported by the Ministry of Education, Science and Technological Development of the Republic of Serbia through the Project Nos. III45012 and ON174004.

\section{References}

[1] G. Bi, C.N. Sun, H.C. Chan, F.L. Ng, C.C. Ma: Mater Design, 60 (2014) 401-408.

[2] A. Jafari, S. M. Abbasi, A. Rahimi, M. Morakabati, M. Seifollahi: Metall Mater Eng, 21 (2015) 167-181.

[3] R. Acharya, S. Das: Metall Mat Trans A 46 (2015) 3864-3875.

[4] A.M. Wusatowska-Sarneka, G.B. Olson, M.J. Blackburn, M. Aindow: J Mater Res, 7 (2003) 2653-2663.

[5] W. W. Milligan, E. L. Orth, J. J. Schirra, M. F. Savage, Superalloys 2004, Eds. K. A. Green et al., TMS (The Minerals, Metals \& Materials Society), Warrendale, Pennsylvania, 2004.

[6] Metals Handbook, $9^{\text {th }}$ Edition, Volume 9, Metallography and Microstructures, Eds. K. Mills et al., ASM (American Society for Metals), Metals Park, Ohio, 1985.

[7] M. T. Jovanović: Metall Mater Eng, 22 (2016) 205-220.

[8] J. L. Smialek, Exploratory Study of Oxidation-Resistant Aluminized Slurry Coatings for IN 100 and WI-52 Superalloys, Retrieved April 10, 2017, from https://ntrs.nasa.gov/archive/nasa/casi.ntrs.nasa.gov/19710015970.pdf

[9] M. Cavacece, P. P. Valentini, L. Vita: Int J Comput Appl T, 28 (2007) 275-280.

[10] N. Ejaz', I. N. Qureshi, S. A. Rizvi: Eng Failure Anal, 18 (2011) 1407-1414.

[11] X. Huang, Z. Zhang, Z. Liu, H. Zhuangqi: Metall Mat Trans A, 28 (1997) 2143 2147.

[12] The Superallys, Eds. C. Sims, W. Hagel, John Wiley, New York, 1972. 
Jovanović et al. - Tensile Properties and Fracture Mechanism of IN-100 Superalloy in High ... 107

[13] R. Jensen, T. Tien: Met Trans A, 16 (1985) 1049-1068.

[14] J. King: Mat Sci Techn, 3 (1987) 750-764.

[15] P. Hicks, C.J. Altsletter: Met Trans A, 21 (1990) 365-380.

[16] H. K. D. H. Bhadeshia, Nickel Based Superalloys, Retrieved April 10, 2017, from http://www.msm.cam.ac.uk/phase-trans/2003/Superalloys/superalloys.html 